\title{
Quasi-Static Ultrasound Elastography
}

\author{
Tomy Varghese \\ Department of Medical Physics, The University of Wisconsin-Madison, Madison, WI-53706, USA
}

\begin{abstract}
Elastography is a new imaging modality where elastic tissue parameters related to the structural organization of normal and pathological tissues are imaged. Basic principles underlying the quasistatic elastography concept and principles are addressed. The rationale for elastographic imaging is reinforced using data on elastic properties of normal and abnormal soft tissues. The several orders of magnitude difference between the elastic modulus of normal and abnormal tissues which is the primary contrast mechanism in elastographic imaging underlines the probability of success with this imaging modality. Recent advances enabling the clinical practice of elastographic imaging in realtime on clinical ultrasound systems is also discussed.

In quasi-static elastography, radiofrequency echo signals acquired before and after a small (about $1 \%$ ) of applied deformation are correlated to estimate tissue displacements. Local tissue displacement vector estimates between small segments of the pre- and post-deformation signals are estimated and the corresponding strain distribution imaged. Elastographic imaging techniques are based on the hypothesis that soft tissues deform more than stiffer tissue, and these differences can be quantified in images of the tissue strain tensor or the Young's modulus.

Clinical applications of quasi-static elastography have mushroomed over the last decade, with the most commonly imaged areas being the breast, prostate, thyroid, cardiac, treatment monitoring of ablation procedures and vascular imaging applications.
\end{abstract}

\section{Keywords}

elastography; elasticity; strain; Young's Modulus; viscoelastic; ultrasound; imaging

\section{Introduction}

Imaging of the viscoelastic properties of tissue for diagnosis and treatment has gained popularity over the last decade because of the ability to provide noninvasive and new diagnostic information [1-29]. Elastography has been likened to manual palpation of tissue, utilized by clinicians for centuries to aid in clinical diagnosis. The clinical popularity of manual palpation is due to the fact that pathologic and stiffness changes in the body are generally well-correlated [30], and irregular and stiffer masses commonly present as warning signs of diseases in organs such as the breast, liver, and prostate. For example, breast scirrhous carcinomas on palpation are felt to be extremely hard nodules [31,32], while liver tissue with cirrhosis is also known to be significantly stiffer than normal healthy liver tissue [33]. However, manual palpation is

\footnotetext{
Address all correspondence to: Tomy Varghese, Department of Medical Physics, 1159 WIMR, 1111 Highland Avenue, The University of Wisconsin-Madison, Madison, WI-53706, USA., Voice: (608)-265-8797, Fax: (608)-262-2413, tvarghese@ wisc.edu.

Publisher's Disclaimer: This is a PDF file of an unedited manuscript that has been accepted for publication. As a service to our customers we are providing this early version of the manuscript. The manuscript will undergo copyediting, typesetting, and review of the resulting proof before it is published in its final citable form. Please note that during the production process errors may be discovered which could affect the content, and all legal disclaimers that apply to the journal pertain.
} 
generally limited to superficial structures and depends largely on the ability of the physician performing the examination. Stiffer masses located deep in the body almost certainly cannot be detected by surface manual palpation. The biggest advancement in the field of tissue elasticity imaging has come with the advent and advances in 'elastography' over the last two decades. The motivation for the use of elastographic techniques stems from the fact that large differences in stiffness or modulus contrast exist between surrounding normal and pathological tissues that may otherwise possess similar image contrasts with conventional clinical imaging modalities.

The term 'Elastography' was coined by Ophir et al. [6], to refer to an ultrasound based imaging technique where local axial strains were estimated by computing the gradient of axial shifts in echo arrival times along the ultrasound beam direction following a quasi-static tissue deformation. Elastography, however has now been used as a more general term to identify methods that image tissue stiffness, using different imaging modalities for example ultrasound, magnetic resonance imaging, optical coherence tomography, X-ray computed tomography [6,26-29], different perturbation techniques to deform tissue [5,6,15,24,34-37] and based on the elasticity parameter being measured or imaged [6,38-40]. In this review, we will focus on quasi-static ultrasound based elastography, since this group of methods form the more commonly used approaches for clinical elasticity imaging.

The practice of quasi-static ultrasound elastography was initially based on the estimation of the axial tissue displacement and strain (corresponding to displacements estimated along both the direction of insonification and tissue deformation) by analyzing ultrasonic radiofrequency echo signals obtained from standard clinical ultrasound diagnostic equipment. Frames of radiofrequency echo-signals acquired before and after a small amount (about $1 \%$ ) of quasistatic deformation were correlated to estimate differential displacements along small data segments or regions of interest using classical time-delay estimation techniques [41,42]. Finally, the axial strain distribution was computed from the gradient of the time-delays or tissue displacements [6].

Algorithms for displacement and strain estimation have progressed from one-dimensional (1D) tracking of the displacement along the insonification and deformation direction $[6,9,43-47]$ to two-dimensional (2D) tracking of the displacement vector within the scan plane [48-52] to three-dimensional (3D) [53-55] methods for tracking the complete displacement vector. These methods can also be classified based on whether they utilize phase information present in the radiofrequency data, namely time-domain cross-correlation $[6,56]$, phase-tracking techniques [7], and phase root tracking methods [24]. Estimators that do not utilize phase information that include optical flow-based speckle tracking [12], analysis of envelope or B-mode signals [57], power spectral methods[45,58,59], and methods like sum amplitude or sum-squared difference that mimic cross-correlation [60,61]. Algorithms to reduce signal decorrelation such as temporal stretching [4-7] of the post-deformation signal to align the radiofrequency peaks with the pre- deformation signal, and multi-compression averaging [6-9], which reduces signal decorrelation by using small deformations, have been utilized. Displacement estimates from the multiple small deformations have been accumulated [8,9], averaged or compounded [69] to improve strain and modulus images. Displacement estimates obtained from multiple angular insonifications have also been averaged to improve the noise properties of the strain images [62,63]. 2D signal processing methods to estimate the displacement vector for data acquired using curvilinear arrays have also been developed [64], since most of the previous algorithms catered to data acquired using linear arrays [48-52]. Displacement estimation in areas where the tissue continuity assumption does not hold namely for vascular tissue have also been developed $[65,66]$, by processing data using a coarse to a fine approach in multiple estimation stages [48,50,51]. Real-time implementations of strain imaging on both custom 
[24] and clinical ultrasound scanners [49], for direct visualization of the strain distribution while scanning the patient has been reported.

Only the axial-strain distribution i.e. strains along the insonification and deformation were imaged until recently [6], while lateral (perpendicular to the beam propagation direction and within the same scan plane) and elevational (perpendicular to the beam propagation direction and scan plane) displacements were usually not estimated. Algorithms have been developed for the estimation of the complete displacement vector and consequently the strain tensor components [67-69]. Since the components of the strain tensor are coupled, accurate estimations of all components are necessary for a complete visualization of the 3D strain distribution incurred in tissue. Lubinski et al. [70] computed local lateral displacements from axial displacements assuming tissue incompressibility (Poisson's ratio of 0.495). Konofagou and Ophir [71] describe a method that utilized weighted interpolation between neighboring radiofrequency A-lines in the lateral direction, along with iterative corrections of lateral and axial displacements to estimate displacement vectors. Another method using radiofrequency data acquired along multiple angular insonification directions (using data from a phased array transducer) was described by Techavipoo et al. [72] to estimate components of the displacement vector, which was later adapted to linear array transducers with electronic beam steering [68].

The normal strain tensor components are also essential in the estimation of other important parameters such as the shear strains $[68,73,74]$ and lateral to axial strain ratios (equivalent to the Poisson's ratio under specific conditions) [39]. Imaging of the shear strain distribution has been utilized to evaluate lesion mobility, in order to differentiate between benign masses such as fibroadenomas that are surrounded by a capsule and loosely attached to background normal tissue and malignant masses that are firmly attached to the normal background tissue through infiltration and the accompanying desmoplastic reaction $[75,76]$. The lateral to axial strain ratio has been utilized as a marker to characterize poroelastic tissue enabling differentiation, for example between normal and edematous tissues [77].

However, the strain tensor distribution is not indicative of the absolute elastic properties of tissue, since it is significantly dependent on the applied deformation or stress distribution $[78,79]$. The additional information with the complete strain tensor distribution can be utilized to obtain unique solutions for the inverse problem $[38,80]$. Many investigators have focused on the estimation of the Young's Modulus in tissue, which if estimated accurately would provides an absolute or quantitative distribution of the underlying tissue elastic properties. However, there are many challenges that have to be addressed for accurate estimation of the Young's modulus, including accurate estimation of the stress distribution and the associated boundary conditions.

Techniques to obtain the local stress distribution patterns using force sensor arrays during tissue deformation have been reported [81]. Temporal and spatial maps of the stress distribution are obtained to evaluate breast masses. The major limitation is the absence of depth dependent information which is being addressed using analytic and finite element methods to model the stress distribution.

The improvements in the quality of the strain and modulus images have dramatically improved over the last two decades. This has led to the commercialization of quasi-static elastography, with four manufactures currently offering strain imaging modes on commercial clinical systems. The following sections lead the reader through a classification of quasi-static elastographic techniques; provide a brief description of the fundamental principles underpinning quasi-static elastography. The review then concludes with a description of the current clinical applications of quasi-static strain and modulus imaging. 


\section{Classification of Quasi-static Elastography}

Elastographic techniques can be broadly classified based on the mechanical stimuli applied into quasi-static and dynamic techniques. Under quasi-static techniques, which are the focus of this review paper, we can further classify the approaches into three categories, namely: 1) Steady-state quasi-static excitation [6-14], 2) Steady-state quasi-static low frequency excitation on the order of 5-10 Hz, and 3) Imaging of steady-state quasi-static deformations due to physiological excitation [35-37], as illustrated in Fig. 1. Dynamic methods can also be further classified into approaches that utilize 1) Harmonic excitations on the order of 10-1000 $\mathrm{Hz}$ [3-5,23,82], and 2) Transient dynamic excitation and subsequent estimation of the transient response [20-22,83].

\section{Steady-State Quasi-static Excitation}

Techniques that utilize a steady state quasi-static excitation of tissue using the ultrasound transducer represent some of the most commonly utilized perturbation approaches to elastographic imaging. Radiofrequency data are collected before and after a known applied deformation, applied as a single deformation step or as multiple deformation steps $[6,7,9,84]$. The pre- and post-deformation data are then compared utilizing different algorithms to estimate differential local displacements between the two tissue states [41,85-87]. Local strains are then estimated from the gradient of the displacement using forward differences or least-square based methods.

Steady-state quasi-static deformations have been applied using either under stepper motor control (with the transducer held in a fixture) or freehand compression using the transducer. Approaches where the deformations are applied using intracavitary probes and ablation electrodes have also been described [88]. Reports on the significant improvement in the strain contrast with electrode displacement when compared to external deformation methods for quasi-static elastography have been presented [89]. In addition, 3D strain imaging [90] and modulus reconstruction (solution of the inverse problem) [91] has also been demonstrated using this approach.

\section{Steady-State Quasi-static Low Frequency Excitation}

The methods described in this category utilize low-frequency deformations on the order of 1$10 \mathrm{~Hz}$, to perturb tissue. Since the deformation frequencies are quite low, these are considered to be quasi-static in nature, and do not generate appreciable shear waves in tissue. Both wellcontrolled [24,34] and freehand-based [15] approaches have been described. Hall et al. [15], described an approach that coupled real-strain strain imaging ( 7 frames per second) and visualization with freehand deformations termed 'palpation imaging'. This approach was implemented initially on the Siemens Elegra, and later on the Antares and the S2000 (Siemens Ultrasound, Seattle, WA, USA), and constitutes one of the earliest commercially available clinical elastography systems on the market.

\section{Steady-State Quasi-static Physiological Excitation}

Physiological stimuli due to respiratory [35], cardiac muscle deformations [36,37] and cardiovascular sources $[9,18,45,92-96]$ have been used for elastographic imaging. Investigators have utilized physiological stimuli to obtain both forward [35-37] and inverse problem [97] solutions for elastography. Physiological deformation sources, however, introduce challenges due to the non-uniform deformations introduced and the need for gating of the data to obtain reproducible results. 


\section{Fundamental Principles Underlying Quasi-Static Elastography}

The success of elastographic imaging is predicated primarily on the several orders of the Young's modulus contrast that exist between normal and abnormal tissue types $[1,2,6]$. This concept is shown as the initial modulus distribution in Fig. 2, whose depiction on an image is sought by all the elasticity imaging methods. A singular advantage of techniques based on exploiting these modulus variations, is that pathological changes in tissue generally alter the underlying elasticity of tissue. However, these same pathological changes may not alter the contrast mechanisms utilized by conventional imaging modalities.

The practice of elastography can be framed either as the solution of the forward problem, that relies on the estimation of the displacement vector, strain tensor or other related parameters, or the inverse problem that attempts to reconstruct the initial modulus distribution as shown in Fig. 2. In general, both the forward and inverse problem solution requires accurate and precise estimation of the local displacements with high spatial resolution and signal-to noise [11]. This is in contrast to dynamic methods for tissue elasticity measurement that utilize variations in the velocity of the shear waves generated in tissue to obtain modulus distributions $[22,98,99]$. Dynamic methods for elasticity imaging and reconstruction are not discussed in this paper, which focuses primarily on quasi-static elastography.

\section{Tissue based Modulus Contrast}

Several groups have reported results on the Young's modulus of soft tissues such as the lung, tendon, breast, prostate, liver, uterus and brain tissue. However, the measurement methods used vary as widely as the values reported [100-105]. Relatively fewer published results exist on human tissues such as breast, prostate, liver, uterus which are of interest for quasi-static elastography [106-111]. Measurements on human tissue stiffness by Sarvazyan et al. [112], Parker et al. [5], Walz et al. [113], Wellman [78], Krouskop [107], and Kiss [114], demonstrate the existence of stiffness contrast among normal tissues, and between normal and pathological tissues in the breast, prostate, thyroid, liver and the uterus.

Krouskop et al. [107] presented initial reproducible results on the modulus variations on breast and prostate tissue and also reported on their nonlinear stress strain behavior. These results were corroborated by Wellman [78], indicating that fibrous breast tissue was stiffer than glandular tissues, which were stiffer than adipose or fatty infiltrated tissues. Krouskop [107], also reported on the Young's modulus values of tumors in the breast with infiltrating ductal carcinomas being significantly stiffer than in situ ductal tumors, which were in turn softer than the glandular, fibrous and fatty tissue in most instances. He also reported on prostate tissue with normal prostate tissue being stiffer than benign prostate hyperplasia and cancers of the prostate being significantly stiffer than the normal prostate.

Young's Modulus measurements on liver tissue by Yeh et al. [108], show that liver tissue stiffness increase with cirrhosis. Hepatic tumors such as cholangiocarcinomas, focal nodular hyperplasia and hemangiomas also exhibit increased stiffness. However, hepatocellular carcinomas were found to be softer than healthy liver [108]. Elastic modulus variations of liver tissue with different fibrosis grades were reported by Wen-Chun et al. [115].

This above section and associated references provides a glimpse into the several order of magnitude in the Young's modulus of normal and pathological tissue types that has been utilized to provide new information on either the modulus of strain distribution in tissue. 


\section{Contrast Transfer Efficiency}

The solution of the forward problem in elastography is based on the utilization of displacement vector and strain tensor images for clinical diagnosis. However, in order to obtain the strain distribution, the underlying tissue has to be deformed or stressed for the modulus distribution to be converted to a strain distribution. The contrast transfer efficiency concept describes the manner by which the modulus distribution is converted to an ideal strain distribution based on purely mechanical considerations as illustrated in Fig. 2. The contrast transfer efficiency concept was utilized by Ponnekanti et al. [116] to illustrate that the axial strain distribution was more efficient in depicting the modulus distribution of stiffer inclusions embedded in a softer background when compared to softer inclusions in a stiffer background. This study was corroborated by Kallel et al. [117] who also developed an analytic model to verify the finite element results presented by Ponnekanti et al. [116].

\section{Statistical Analysis of Strain Estimation}

Tradeoffs in the displacement vector and strain tensor estimation process from the noisy preand post-deformed ultrasound radiofrequency signals has been described statistically using the 'Strain Filter' concept $[11,47,118]$. The strain filter has been defined as the statistical upper bound of the variation in the elastographic signal-to-noise ratio $\left(S N R_{e}\right)$ (ratio of the mean strain estimate to the theoretical lower bound of the standard deviation [41,85-87]) as a function of the applied deformation. The strain filter provides a transfer characteristic that describes the filtering process in the strain domain that enables visualization of only a limited range of the local strains generated in tissue as a function of the applied deformation. The strain filter concept allows prediction of this limited range of strains based on the ultrasound system parameters and the signal processing algorithms and parameters used for strain estimation [11].

The forward problem in quasi-static elastography as illustrated in Fig. 2, is based on the three concepts or principles discussed in the preceding paragraphs [11]. Conversion of the underlying modulus distribution to the strain distribution is clearly elucidated using the contrast transfer efficiency concept to obtain the ideal strain distribution. The statistical analysis of strain estimation described using the strain filter concept, demonstrates the tradeoffs between the system parameters and signal processing approaches in depicting the strain visualized in the estimated strain image. Finally, the combination of the contrast transfer efficiency and the strain filter principles lead to the prediction of the upper bound on the contrast-to-noise ratios obtainable in strain images, which quantifies the forward problem $[119,120]$.

\section{Spatial Resolution for Quasi-static Strain Imaging}

The cross-correlation window length and the overlap between adjacent processing windows are two of the primary signal-processing parameters that impact the axial resolution obtained with quasi-static strain imaging [10,121-123]. The length of the cross-correlation window at a fixed overlap was initially used as a measure of the axial resolution [10]. Alam et al. [121] demonstrated that axial resolution can be expressed as a bilinear function of the window length and overlap, with the overlap being the more important factor. Longer duration windows also provide improved sensitivity to strain estimation, and the ability to estimate a larger range of local strains and improved $S N R_{e}$ and $C N R_{e}$ (as long as the increased signal decorrelation within the gated window was negated by the increased information content) at the expense of spatial resolution [47]. In general, we can tradeoff reductions in the spatial resolution to significant improvements in the $S N R_{e}$ and $C N R_{e}$ and vice-versa [11,124]. In a recent paper, Righetti et al. [122] illustrated that the ultimate limit on the axial resolution was directly proportional to the wavelength or inversely proportional to the fractional bandwidth of the ultrasound system. On the other hand, the ultrasound lateral beam width limits the achievable lateral resolution for quasi-static strain imaging [125]. In a similar manner, the elevational beam-width would impact 
the elevational resolution. The axial, lateral and elevational resolution become important with the use of 2D transducers for 3D strain imaging [55].

\section{The Inverse Problem in Quasi-Static Elastography}

Solution of the inverse problem in quasi-static elastography involve the utilization of the estimated displacement vector and strain tensor information to reconstruct the underlying modulus distribution as illustrated in Fig. 2. Accurate and reproducible determination of the modulus distribution would be the preferred image for clinical diagnosis since it would provide a direct image of the underlying modulus distribution. In addition, it would provide quantitative information as opposed to the qualitative information provided with displacement vector and strain tensor images, which depend to a large extent on the applied deformation.

However, the solution of the inverse problem is not straightforward and requires additional information on both the boundary conditions in effect during the applied deformation and the local stress distribution in tissue. Unfortunately the local stress distribution is generally unknown other than at the tissue surface where the deformation is applied. The difficulty in the computation of the local stress distribution within the tissue is a major stumbling block for modulus reconstruction. This has led to two different approaches for modulus reconstruction described in the literature, namely 1) Iterative modulus reconstruction $[38,91,126]$ based on assumption on the uniformity of the stress distribution [38]., and 2) model (finite element or analytic) based reconstruction $[97,127]$ approaches.

Iterative methods $[38,91,126]$ attempt to converge to a final modulus distribution based on the estimated displacement field using assumptions on the boundary conditions and uniformity of the stress distribution. Kallel et al. [38] utilized a Newton-Raphson algorithm to find the modulus distribution that provides the best reproduction of the estimated axial displacement field using Tikhonov regularization to achieve convergence in 8-10 steps. Model based methods $[97,127]$ on the other hand utilize prior information on the geometry of the imaged object to obtain analytic or finite element solutions that are utilized to aid in the convergence.

The ill-posed nature of the inverse solutions also introduce large noise artifacts and may result in non-unique solutions of the underlying modulus distribution [80]. Barbone and Bamber [80] demonstrate that knowledge of only the displacement and boundary conditions remain insufficient to obtain unique solutions of the modulus distribution. Additional information such as the modulus itself or its derivatives on the boundary and stress distributions or additional strain tensor information are essential for unique modulus reconstruction $[38,80]$.

\section{Clinical Applications of Quasi-Static Elastography}

Although quasi-static elastography has been under development over the last two decades, it is only recently that commercial clinical ultrasound system manufacturers have introduced clinical products based on elastography. The availability of elastography modes on clinical system will rapidly increase clinical applications and organ system where elastography will be utilized in the future.

In general, two criteria have to be satisfied for successful clinical elastographic imaging, namely the ability to apply a quasi-static deformation and the ability to ultrasonically image the tissue being deformed. Superficial organs such as skin, breast, neck, thyroid, lymph nodes, deep vein thrombi are some of the best candidates for strain or modulus imaging $[13,15,75$, 76,128-131]. Approaches to deform organs located deeper in the body have been reported, that use intracavitary ultrasound transducers, intracavitary balloons for imaging the prostate gland [132,133], saline infusion for imaging the uterus [134] etc.. As described previously, physiological stimuli have been utilized to image the heart, vasculature, liver, and the coronary 
and carotid arteries [36,37,51,135-140]. We discuss some of the clinical applications of quasistatic strain and modulus imaging in the following paragraphs.

\section{Breast}

Strain $[13,15,75,76,128-130]$ and modulus [40] imaging of masses in the breast have been widely reported in the literature. Strain imaging in the breast was one of the first reported clinical application of quasi-static elastography [13], since many breast lesions are superficial and are known to be significantly stiffer than surrounding normal breast tissue [107]. Strain imaging of the breast has been reported using well-controlled stepper motor based deformations (both single and multiple deformation steps) [13], real-time freehand palpation [15], and also the utilization of physiological deformation of the left breast due to cardiac activity.

Some of the early parameters utilized to differentiate benign from malignant masses was also reported on breast masses to differentiate malignant breast tumors from benign fibroadenomas. Since breast tumors are significantly stiffer (depicted in a darker gray scale as opposed to the lighter gray scale used for softer tissue) than surrounding normal tissue, the stiffness or strain contrast was initially used to differentiate breast masses[13], as shown in Fig. 3 for a patient with an invasive ductal carcinoma. Note that although the margins of the mass are not clearly visualized in the B-mode image in Fig. 3(a), it is clearly seen in the axial strain image in Fig. 3 (b) as a darker (stiffer) region. In addition, it was found that invasive cancers in the breast were depicted as larger areas of stiffness in the strain images, when compared to the corresponding B-mode images [13], observed from comparing Figs, 3 (a) and (b). The increased stiffer regions observed in the strain images were hypothesized to be due to the desmoplastic reaction from the infiltration of the tumor cells into surrounding breast tissue. A second parameter referred to as the 'size ratio' derived from the ratio of the lesion dimensions derived from the strain and B-mode images was then proposed to differentiate between benign fibroadenomas from malignant tumors[13,15]. Another parameter utilized in the differentiation is related to lesion mobility; since cancers are firmly attached to surrounding tissue, when compared to fibroadenomas that are more mobile and hence slip during the applied deformation $[75,76]$. Parameters related to the normalized shear strain around the breast masses haven been utilized to quantify the attachment of the mass or lesion to the surrounding tissue as shown in Fig. 3(c). Observe the large shear strain areas (blue and red regions) that are clearly seen towards the top of the mass margins are indicative of firmly attached masses [75,76]. Elastography also provides clear classification of cystic masses which are depicted with a central decorrelation spot appearing as a bright spot or region on the strain image. Finally, methods to assess the viscoelastic response by evaluating tissue creep have also been described [141].

\section{Thyroid}

The thyroid gland is another superficial gland that is a viable target for quasi-static elastography. Due to the accessibility of the thyroid gland, external deformation of the thyroid using the ultrasound transducer has been utilized by several groups [131,142,143].

Deformations introduced from pulsations due to blood flow through the carotid artery has also been utilized as a deformation source [95].

\section{Lymph Nodes}

Assessments of the stiffness of lymph nodes represent another clinical application area for quasi-static elastography due to the superficial nature of these nodes enabling application of external deformations for strain imaging [144]. 


\section{Deep Vein thrombosis}

Deep vein thrombi or blood clots are known to progressively increase in stiffness with age, and a means to stage thrombi age is essential in their treatment. Quasi-static modulus imaging has been utilized to determine the thrombi age, since newer clots can be treated more effectively when compared to older clots [145].

Prostate

Another area where in-vivo strain imaging has made inroads is in the imaging of the prostate gland. The prostate gland presents a more challenging environment for the application of strain imaging, due to its location, primarily for the application of the deformation required for strain imaging. Deformation states of the prostate has been varied utilizing different levels of saline within the balloon [146], and deformations applied using the trans-rectal ultrasound transducer (TRUS) [147]. The TRUS transducer also provides data in a curvilinear format when compared to linear array transducers utilized for the breast, small parts and imaging of the carotid.

\section{Uterine strain imaging}

Evaluation of focal uterine masses has also been explored using trans-vaginal ultrasound transducer (TVUS) and utilizing saline infusion to provide the deformation [134]. Ex-vivo quasi-static strain imaging of different uterine pathology has been reported in the literature [148]. Another application area for strain and modulus imaging is the evaluation of cervical stiffness $[149,150]$ which may have implications for the evaluation of patients at risk for preterm labor.

\section{Treatment Monitoring of Ablative therapies}

Treatment monitoring of ablative therapies is probably one of the more natural applications for strain and modulus elastography, since heating tissue induce denaturation of proteins which in turn elevates the Young's modulus of ablated tissue. Strain imaging has been utilized to monitor ablative therapies such as high-intensity focused ultrasound [146], radiofrequency and microwave ablation procedures [88]. An interesting offshoot is the utilization of the radiofrequency or microwave electrode itself to introduce the quasi-static deformation for both strain [88] and modulus [91] imaging. This method has been utilized for in vivo imaging of thermal lesions in the kidney and liver [132,133]. 3D strain imaging has also been reported with electrode displacement elastography [90]. An example of in-vivo electrode displacement based strain imaging is illustrated in Fig, 4, for a thermal lesion created in the liver of a porcine animal model using a Cool-tip ${ }^{\mathrm{TM}}$ radiofrequency ablation system (Valleylab, Boulder, CO).

\section{Monitoring of Edema}

Quasi-static elastography has also been utilized for imaging the poroelastic properties of tissue that accumulate fluid, for example for evaluating lymphedema, which involves an abnormal interstitial accumulation of lymphatic fluid causing tissue swelling [39,77,151]. Variations in the ratio of the lateral to axial strain values with deformation provide estimates of the fluid content and the ability to differentiate between normal and edematous tissues [77].

\section{Intravascular Strain Imaging}

Intravascular ultrasound (IVUS) based strain imaging of coronary arteries using pulsations introduced due to cardiac activity has been widely described in the literature and is probably the most common clinical application involving physiological stimuli[9,18,45,92,93]. The most common implementation utilizes radiofrequency data acquired at two different intraluminal pressure levels near diastole. IVUS elastography involves the acquisition of highfrequency (20 MHz or higher) radiofrequency data from single element or array transducers 
located at the tip of a catheter that is inserted into the coronary artery to be evaluated. In addition to the strain distribution modulus maps have also been generated [152]. One of the challenges in intravascular elastography and carotid strain imaging described in the next sub-section is the identification and differentiation of 'vulnerable plaque' or plaque prone to rupture [139].

\section{Carotid Strain Imaging}

Most of the reported strain and modulus imaging studies for plaque characterization utilize intravascular ultrasound on coronary arteries $[139,140]$ as described above. However, the carotid artery is another superficial location that provides easy access to clinical ultrasound equipment with linear array transducers [51,135-138], and is also amenable to strain imaging. Figure 5, presents a B-mode and axial strain image for a patient with a strip of softer plaque observed at a depth of $2 \mathrm{~cm}$ and extending from 1.5 to $4 \mathrm{~cm}$. The strain image also classifies the remainder of the plaque in the vessel as relatively stiffer plaque visualized as the mid-gray gray scale in Fig. 5(b) $[51,135,138]$. Investigators have reported on estimation of the Young's modulus by solving the inverse problem using the estimated strains and mechanical models of the carotid artery [137]. However, both the carotid and coronary artery models have to account for hemodynamic parameters that vary significantly with stenosis for inverse problem solutions.

\section{Cardiac Elastography}

Cardiac-elastography or myocardial strain imaging where the strain distribution is imaged over the entire contraction and relaxation of the heart (cardiac cycle) $[36,37]$ is another clinical application that utilizes physiological stimuli. B-mode speckle tracking for strain imaging is currently utilized, primarily due to limitations associated with tissue Doppler-derived velocity and strain estimates [153-155]. Both General Electric Medical Systems (GE Healthcare, Milwaukee, WI, USA) and Siemens (Siemens Ultrasound, Mountain View, CA, USA) have rolled out clinical cardiac ultrasound systems equipped with 2D speckle tracking methods for strain imaging. Strain imaging that utilizes radiofrequency signals would provide significantly improved strain sensitivity, when compared to the B-mode based approaches [36,156]. A shortaxes B-mode and strain image obtained using radiofrequency data, estimated using a hybrid 2D algorithm developed for curvilinear transducers [64] is shown in Fig. 6. Observe that the strains depicted in the image for the cardiac muscle is mostly compressive (blue color), since this image was obtained during systole. However, the frame rates at which radiofrequency data are acquired is an important factor to obtain unbiased and robust estimation of tissue displacements and strain [157]. Frame rates for B-mode data are significantly higher than that for radiofrequency data. Approaches to obtain high precision radial, circumferential and longitudinal strains are also necessary for the widespread clinical application of this modality. Estimation of principal strain components, which are angle-independent, is one such approach that may provide reproducible diagnostic measures for evaluating cardiac disease [158].

\section{Respiratory and Cardiac stimuli for Abdominal Strain Imaging}

Deformations of the liver and other abdominal organs introduced due to respiration, for example diaphragmatic deformations has been utilized for imaging thermal lesions created $n$ the liver [35]. Cardiovascular motion [94], has also been utilized for in-vivo elastographic imaging of the liver. However, all of these approaches require gating of the data acquisition to the respiratory or cardiac waveform to ensure similar deformation increments and for reproducible imaging.

\section{Conclusion}

The last two decades have seen tremendous advances in the development and clinical practice of quasi-static ultrasound elastography in the depiction of quality displacement vector, strain 
tensor and modulus distributions. Currently four different commercial ultrasound system manufacturer's offer quasi-static based strain imaging modes on their clinical systems. Palpation based strain imaging is currently available on both the Siemens Antares and the S2000 systems (Siemens Ultrasound, Seattle, WA, USA). Hitachi Medical systems (Hitachi Ltd., Tokyo, Japan) provide elastography modes on their scanners. Ultrasonix Medical Corporation (Vancouver, BC, Canada) recently introduced the SonixTOUCH system with an elastography mode. General Electric Medical Systems (GE Healthcare, Milwaukee, WI, USA) and Siemens have also introduced 2D speckle tracking on their cardiac ultrasound systems. The availability of quasi-static based strain imaging modes on clinical system will further spur the development of this new imaging modality, since it provides additional information not present with current clinical imaging modalities.

Although, quantitative i.e. modulus imaging with quasi-static elastography would provide the best visualization of the underlying modulus distribution in tissue, this mode requires additional development to reduce noise artifacts and to obtain unique solutions. This would require the development of techniques for accurate and precise estimate of both the local strain and stress distributions at high spatial resolutions, and research is ongoing in this area. We anticipate continued improvements in the spatial resolution and signal to noise ratios in the estimated strain tensor distribution with improved algorithms and processing techniques. Development of methods for accurate estimation of the local stress distribution has to be developed, with techniques that use force sensors on ultrasound transducers under evaluation.

This paper does not review dynamic elastography based methods, which have also made significant strides over the last decade. Commercialization of these approaches include the FibroScan ${ }^{\circledR}$ system developed by Echosens (Echosens SA, Paris, France), a device that tracks shear wave speed for monitoring and staging hepatic fibrosis [159], and the S2000 (Siemens Ultrasound, Seattle, WA, USA) equipped with the Virtual Touch(TM) software a acoustic radiation force based imaging mode. Some of these recent developments to obtain modulus estimates of small regions in tissue may enable more accurate staging of diffuse diseases. Several excellent review papers exist in the literature that would provide the interested reader with additional insights into this novel imaging modality [160-164].

\section{Acknowledgments}

I would like to thank Dr. Min Rao, Ph.D, Dr. Hao Chen Ph.D, Mr. Matthew McCormick, Mr. Nick Rubert and Ms. Haiyan Xu for providing the results used in this paper. This work was funded in part by NIH grants R01 CA112192-02, R21 CA140939-01 and Komen Foundation grant BCTR0601153.

\section{References}

1. Dickinson RJ, Hill CR. Measurement of soft tissue motion using correlation between A-scans. Ultrasound Med Biol 1982;8:263-71. [PubMed: 7101574]

2. Wilson LS, Robinson DE. Ultrasonic measurement of small displacements and deformations of tissue. Ultrasonic Imaging 1982;4:71-82. [PubMed: 7199773]

3. Krouskop TA, Dougherty DR, Vinson FS. A pulsed Doppler ultrasonic system for making noninvasive measurements of the mechanical properties of soft tissue. Journal of Rehabilitation Research \& Development 1987;24:1-8. [PubMed: 3295197]

4. Yamakoshi Y, Sato J, Sato T. Ultrasonic Imaging of internal vibration of soft tissue under forced vibration. IEEE Trans Ultrason Ferroel Freq Cont 1990;37:45-53.

5. Parker KJ, Huang SR, Musulin RA, Lerner RM. Tissue response to mechanical vibrations for 'sonoelasticity imaging'. Ultrasound Med Biol 1990;16:241-6. [PubMed: 2194336]

6. Ophir J, Cespedes I, Ponnekanti H, Yazdi Y, Li X. Elastography: a quantitative method for imaging the elasticity of biological tissues. Ultrasonic Imaging 1991;13:111-34. [PubMed: 1858217] 
7. O'Donnell M, Skovoroda AR, Shapo BM. Measurement of arterial wall motion using Fourier based speckle tracking algorithms. Proc IEEE Ultras Symp 1991:1101-1104.

8. Ophir J, Cespedes EI, Garra BS, Ponnekanti H, Huang Y, Maklad N. Elastography: ultrasonic imaging of tissue strain and elastic modulus in vivo. Invited Paper \& Review, European Journal of Ultrasound 1996;3:49-70.

9. O’Donnell M, Skovoroda AR, Shapo BM, Emelianov SY. Internal displacement and strain imaging using ultrasonic speckle tracking. IEEE Trans Ultrason Ferroel Freq Cont 1994;41:314-25.

10. Cespedes, EI. Elastography: Imaging of Biological Tissue Elasticity. University of Houston; 1993.

11. Varghese T, Ophir J, Konofagou E, Kallel F, Righetti R. Tradeoffs in elastographic imaging. Ultrasonic Imaging 2001;23:216-48. [PubMed: 12051276]

12. Bertrand, M.; Meunier, M.; Doucet, M.; Ferland, G. Ultrasonic biomechanical strain gauge based on speckle tracking. IEEE Ultrasonics Symposium; 1989. p. 859-864.

13. Garra BS, Cespedes EI, Ophir J, Spratt SR, Zuurbier RA, Magnant CM, Pennanen MF. Elastography of breast lesions: initial clinical results. Radiology Jan;1997 202:79-86. [PubMed: 8988195]

14. Ophir J, Garra B, Kallel F, Konofagou E, Krouskop T, Righetti R, Varghese T. Elastographic imaging. Ultrasound in Medicine and Biology 2000;26(suppl):S23-9. [PubMed: 10794867]

15. Hall TJ, Zhu Y, Spalding CS. In vivo real-time freehand palpation imaging. Ultrasound Med Biol 2003;29:427-35. [PubMed: 12706194]

16. Hiltawsky KM, Kruger M, Starke C, Heuser L, Ermert H, Jensen A. Freehand ultrasound elastography of breast lesions: clinical results. Ultrasound Med Biol 2001;27:1461-9. [PubMed: 11750744]

17. Insana MF, Hall TJ, Chaturvedi P, Kargel C. Ultrasonic properties of random media under uniaxial loading. Journal of the Acoustical Society of America 2001;110:3243-51. [PubMed: 11785825]

18. de Korte CL, Ignacio Cespedes EI, van der Steen AF, Lancee CT. Intravascular elasticity imaging using ultrasound: feasibility studies in phantoms. Ultrasound Med Biol 1997;23:735-46. [PubMed: 9253821]

19. Bamber JC, Bush NL. Freehand elasticity imaging using speckle decorrelation rate. Acoustic Imaging 1996;22:285-292.

20. Walker WF. Internal deformation of a uniform elastic solid by acoustic radiation force. J Acoust Soc Am 1999;105:2508-18. [PubMed: 10212432]

21. Nightingale KR, Nightingale RW, Palmeri ML, Trahey GE. A finite element model of remote palpation of breast lesions using radiation force: factors affecting tissue displacement. Ultrason Imaging 2000;22:35-54. [PubMed: 10823496]

22. Sarvazyan AP, Rudenko OV, Swanson SD, Fowlkes JB, Emelianov SY. Shear wave elasticity imaging: a new ultrasonic technology of medical diagnostics. Ultrasound Med Biol Nov;1998 24:1419-35. [PubMed: 10385964]

23. Fatemi M, Greenleaf JF. Probing the dynamics of tissue at low frequencies with the radiation force of ultrasound. Physics in Medicine and Biology 2000;45:1449-64. [PubMed: 10870703]

24. Pesavento A, Lorenz A, Siebers S, Ermert H. New real-time strain imaging concepts using diagnostic ultrasound. Phys Med Biol 2000;45:1423-35. [PubMed: 10870701]

25. Lizzi FL, Muratore R, Deng CX, Ketterling JA, Alam SK, Mikaelian S, Kalisz A. Radiation-force technique to monitor lesions during ultrasonic therapy. Ultrasound Med Biol 2003;29:1593-605. [PubMed: 14654155]

26. Plewes DB, Betty I, Urchuk SN, Soutar I. Visualizing tissue compliance with MR imaging. Journal of Magnetic Resonance Imaging 1995;5:733-8. [PubMed: 8748495]

27. Muthupillai R, Lomas DJ, Rossman PJ, Greenleaf JF, Manduca A, Ehman RL. Magnetic resonance elastography by direct visualization of propagating acoustic strain waves. Science 1995;269:18547. [PubMed: 7569924]

28. Fowlkes JB, Emelianov SY, Pipe JG, Skovoroda AR, Carson PL, Adler RS, Sarvazyan AP. Magneticresonance imaging techniques for detection of elasticity variation. Medical Physics 1995;22:17718. [PubMed: 8587532]

29. Schmitt JM. OCT elastography: imaging microscopic deformation and strain of tissue. Optics Express 1998;3 
30. Fung, YG. Biomechanical Properties of Living Tissues. Vol. chapter 7. New York: Springer Verlag; 1981.

31. Anderson, WAD. Pathology. C.V. Mosby; St. Louis: 1953.

32. Krouskop TA, Wheeler TM, Kallel F, Garra BS, Hall T. Elastic moduli of breast and prostate tissues under compression. Ultrasonic Imaging 1998;20:260-74. [PubMed: 10197347]

33. Anderson, WAD. Pathology. St. Louis, MO: C. V. Mosby Co; 1953.

34. Turgay E, Salcudean S, Rohling R. Identifying the mechanical properties of tissue by ultrasound strain imaging. Ultrasound Med Biol 2006;32:221-35. [PubMed: 16464668]

35. Varghese T, Shi H. Elastographic imaging of thermal lesions in liver in-vivo using diaphragmatic stimuli. Ultrason Imaging 2004;26:18-28. [PubMed: 15134391]

36. Varghese T, Zagzebski JA, Rahko P, Breburda CS. Ultrasonic imaging of myocardial strain using cardiac elastography. Ultrason Imaging 2003;25:1-16. [PubMed: 12747424]

37. Konofagou EE, D'Hooge J, Ophir J. Myocardial elastography-a feasibility study in vivo. Ultrasound in Medicine and Biology 2002;28:475-82. [PubMed: 12049961]

38. Kallel F, Bertrand M. Tissue elasticity reconstruction using linear perturbation method. IEEE Transactions on Medical Imaging 1996;15:299-313. [PubMed: 18215911]

39. Konofagou EE, Harrigan TP, Ophir J, Krouskop TA. Poroelastography: imaging the poroelastic properties of tissues. Ultrasound Med Biol Oct;2001 27:1387-97. [PubMed: 11731052]

40. Oberai AA, Gokhale NH, Goenezen S, Barbone PE, Hall TJ, Sommer AM, Jiang J. Linear and nonlinear elasticity imaging of soft tissue in vivo: demonstration of feasibility. Phys Med Biol 2009;54:1191-207. [PubMed: 19182325]

41. Quazi AH. An overview of the time delay estimate in active and passive systems for target localization. IEEE Trans Acoust Speech, Sig Proc 1981;29:527-533.

42. Weinstein E, Weiss A. Fundamental limitations in passive time delay estimation Part II: Wide-band systems. IEEE Trans Acoust Speech Sig Proc 1984;31:1064-1078.

43. Bilgen M, Insana MF. Deformation models and correlation analysis in elastography. Journal of the Acoustical Society of America 1996;99:3212-24. [PubMed: 8642127]

44. Chen EJ, Adler RS, Carson PL, Jenkins WK, brien JOWD. Ultrasound tissue displacement imaging with application to breast cancer. Ultrasound in Medicine \& Biology 1995;21:1153-62. [PubMed: 8849830]

45. Talhami HE, Wilson LS, Neale ML. Spectral tissue strain: a new technique for imaging tissue strain using intravascular ultrasound. Ultrasound Med Biol 1994;20:759-72. [PubMed: 7863565]

46. Pesavento A, Perrey C, Krueger M, Ermert H. A time-efficient and accurate strain estimation concept for ultrasonic elastography using iterative phase zero estimation. IEEE Trans Ultrason Ferroel Freq Cont 1999;46:1057-67.

47. Varghese T, Bilgen M, Ophir J. Multiresolution imaging in elastography. IEEE Trans Ultrason Ferroel Freq Cont 1998;45:65-75.

48. Chaturvedi P, Insana MF, Hall TJ. 2-D companding for noise reduction in strain imaging. IEEE Transactions on Ultrasonics, Ferroelectrics and Frequency Control 1998;45:179-91.

49. Zhu Y, Hall T. A modified block matching method for real-time freehand strain imaging. Ultrason Imaging 2002;24:161-176. [PubMed: 12503771]

50. Pellot-Barakat C, Frouin F, Insana MF, Herment A. Ultrasound elastography based on multiscale estimations of regularized displacement fields. IEEE Trans Med Imaging 2004;23:153-163. [PubMed: 14964561]

51. Shi H, Varghese T. Two-Dimensional Multi-level Strain Estimation for Discontinuous Tissue. Phys Med Biol 2007;52:389-401. [PubMed: 17202622]

52. Jiang J, Hall TJ. A parallelizable real-time motion tracking algorithm with applications to ultrasonic strain imaging. Phys Med Biol 2007;52:3773-3790. [PubMed: 17664576]

53. Patil AV, Garson CD, Hossack JA. 3D prostate elastography: algorithm, simulations and experiments. Phys Med Biol 2007;52:3643-3663. [PubMed: 17664564]

54. Chen X, Xie H, Erkamp R, Kim K, Jia C, Rubin JM, O’Donnell M. 3-D correlation-based speckle tracking. Ultrason Imaging 2005;21:21-36. [PubMed: 16003924] 
55. Rao M, Varghese T. Correlation analysis of three-dimensional strain imaging using ultrasound twodimensional array transducers. J Acoust Soc Am 2008;124:1858-65. [PubMed: 19045676]

56. Cespedes I, Ophir J, Ponnekanti H, Maklad N. Elastography: elasticity imaging using ultrasound with application to muscle and breast in vivo. Ultrasonic Imaging 1993;15:73-88. [PubMed: 8346612]

57. Varghese T, Ophir J. Characterization of elastographic noise using the envelope of echo signals. Ultrasound Med Biol 1998;24:543-55. [PubMed: 9651964]

58. Varghese T, Konofagou EE, Ophir J, Alam SK, Bilgen M. Direct strain estimation in elastography using spectral cross-correlation. Ultrasound Med Biol 2000;26:1525-37. [PubMed: 11179627]

59. Konofagou EE, Varghese T, Ophir J, Alam SK. Power spectral strain estimators in elastography. Ultrasound in Medicine and Biology 1999;25:1115-29. [PubMed: 10574343]

60. Hoyt K, Forsberg F, OJ. Comparison of shift estimation strategies in spectral elastography. Ultrasonics 2006;44:99-108. [PubMed: 16243373]

61. Bohs LN, Friemel BH, McDermott BA, Trahey GE. A real time system for quantifying and displaying two-dimensional velocities using ultrasound. Ultrasound Med Biol 1993;19:751-61. [PubMed: 8134976]

62. Rao M, Chen Q, Shi H, Varghese T. Spatial-Angular Compounding for Elastography Using Beam Steering on Linear Array Transducers. Med Phys 2006;33:618-26. [PubMed: 16878565]

63. Techavipoo U, Chen Q, Varghese T, Zagzebski JA, Madsen EL. Noise reduction using spatial-angular compounding for elastography. IEEE Trans Ultrason Ferroel Freq Cont 2004;51:510-520.

64. Chen H, Varghese T. Multi-Level Hybrid 2-D Strain Imaging Algorithm for Ultrasound Sector/Phased Arrays. Medical Physics 2009;36:2098-2106. [PubMed: 19610299]

65. Zhu Y, Chaturvedi P, Insana MF. Strain imaging with a deformable mesh. Ultrasonic Imaging 1999;21:127-41. [PubMed: 10485566]

66. Maurice RL, Bertrand M. Lagrangian speckle model and tissue-motion estimation-theory [ultrasonography]. IEEE Trans Med Imag 1999;18:593-603.

67. Konofagou E, Ophir J. A new elastographic method for estimation and imaging of lateral displacements, lateral strains, corrected axial strains and Poisson's ratios in tissues. Ultrasound in Medicine and Biology 1998;24:1183-99. [PubMed: 9833588]

68. Rao M, Chen Q, Shi H, Varghese T, Madsen EL, Zagzebski JA, Wilson T. Normal and Shear Strain Estimation Using Beam Steering on Linear-Array Transducers. Ultrasound Med Biol 2007;33:5766. [PubMed: 17189047]

69. Techavipoo U, Chen Q, Varghese T, Zagzebski J. Estimation of displacement vectors and strain tensors in elastography using angular insonifications. IEEE Trans Med Imaging 2004;23:1479-1489. [PubMed: 15575406]

70. Lubinski MA, Emelianov SY, Raghavan KR, Yagle AE, Skovoroda AR, ODM. Lateral displacement estimation using tissue incompressibility. IEEE Transactions on Ultrasonics, Ferroelectrics and Frequency Control 1996;43:247-56.

71. Konofagou E, Ophir J. A new elastographic method for estimation and imaging of lateral displacements, lateral strains, corrected axial strains and Poisson's ratios in tissues. Ultrasound Med Biol 1998;24:1183-99. [PubMed: 9833588]

72. Techavipoo U, Chen Q, Varghese T, Zagzebski JA. Estimation of displacement vectors and strain tensors in elastography using angular insonifications. IEEE Trans Med Imaging 2004;23:1479-89. [PubMed: 15575406]

73. Konofagou EE, Harrigan T, Ophir J. Shear strain estimation and lesion mobility assessment in elastography. Ultrasonics 2000;38:400-4. [PubMed: 10829696]

74. Rao M, Varghese T, Madsen EL. Shear strain imaging using shear deformations. Med Phys 2008;35:412-23. [PubMed: 18383661]

75. Thitaikumar A, Mobbs LM, Kraemer-Chant CM, Garra BS, Ophir J. Breast tumor classification using axial shear strain elastography: a feasibility study. Phys Med Biol 2008;53:4809-23. [PubMed: 18701768]

76. Rao, M.; Baker, S.; Sommer, AM.; Varghese, T.; Sisney, GA.; Herd, MT.; Burnside, ES.; Hall, TJ. Shear strain elastography for breast mass differentiation (abstract). 7th International Conference on the Ultrasonic Measurement and Imaging of Tissue Elasticity; Austin, TX. 2008. 
77. Righetti R, Garra BS, Mobbs LM, Kraemer-Chant CM, OJ, Krouskop TA. The feasibility of using poroelastographic techniques for distinguishing between normal and lymphedematous tissues in vivo. Phys Med Biol 2007;52:6525-41. [PubMed: 17951860]

78. Wellman PS, Dalton EP, Krag D, Kern KA, Howe RD. Tactile imaging of breast masses: first clinical report. Arch Surg 2001;136:204-8. [PubMed: 11177142]

79. Sarvazyan A. Mechanical imaging: a new technology for medical diagnostics. Int J Med Inform 1998;49:195-216. [PubMed: 9741894]

80. Barbone PE, Bamber JC. Quantitative elasticity imaging: what can and cannot be inferred from strain images. Phys Med Biol 2002;47:2147-64. [PubMed: 12118606]

81. Egorov V, Sarvazyan AP. Mechanical imaging of the breast. IEEE Trans Med Imaging 2008;27:127587. [PubMed: 18753043]

82. Dutt V, Kinnick RR, Muthupillai R, Oliphant TE, Ehman RL, Greenleaf JF. Acoustic shear-wave imaging using echo ultrasound compared to magnetic resonance elastography. Ultrasound Med Biol 2000;26:397-403. [PubMed: 10773369]

83. Sandrin L, Catheline S, Tanter M, Hennequin X, Fink M. Time-resolved pulsed elastography with ultrafast ultrasonic imaging. Ultrasonic Imaging 1999;21:259-72. [PubMed: 10801211]

84. Ophir J, Kallel F, Varghese T, Bertrand M, Cespedes I, Ponnekanti H. Elastography: a systems approach. International Journal of Imaging Systems and Technology 1997;8:89-103.

85. Weinstein E, Weiss A. Fundamental limitations in passive time delay estimation Part II: Wide-band systems. IEEE Trans Acoust Speech, Sig Proc 1984;31:1064-1078.

86. Knapp CH, Carter GC. The generalized correlation method for estimation of time delay. IEEE Trans Acoust Speech, Sig Proc 1976;24:320-327.

87. Walker FW, Trahey GE. A fundamental limit on delay estimation using partially correlated speckle signals. IEEE Trans Ultrason Ferroel Freq Cont 1995;42:301-308.

88. Varghese T, Zagzebski JA, Lee FT Jr. Elastographic imaging of thermal lesions in the liver in vivo following radiofrequency ablation: preliminary results. Ultrasound Med Biol 2002;28:1467-73. [PubMed: 12498942]

89. Bharat S, Varghese T. Contrast-transfer improvement for electrode displacement elastography. Phys Med Biol 2006;51:6403-18. [PubMed: 17148825]

90. Bharat S, Fisher TG, Varghese T, Hall TJ, Jiang J, Madsen EL, Zagzebski JA, Lee FTJ. Threedimensional electrode displacement elastography using the Siemens C7F2 fourSight fourdimensional ultrasound transducer. Ultrasound Med Biol 2008;34:1307-16. [PubMed: 18374467]

91. Jiang, J.; Varghese, T.; Brace, C.; Madsen, EL.; Hall, TJ.; Bharat, S.; Hobson, MA.; Zagzebski, JA.; Lee, FT, Jr. Young's Modulus Reconstruction for Radio-Frequency Ablation Electrode-Induced Displacement Fields: A Feasibility Study. IEEE Trans Med Imag; 2009.

92. de Korte CL, van der Steen AF, Cespedes EI, Pasterkamp G. Intravascular ultrasound elastography in human arteries: initial experience in vitro. Ultrasound Med Biol Mar;1998 24:401-8. [PubMed: 9587995]

93. Ryan LK, Foster FS. Ultrasonic measurement of differential displacement and strain in a vascular model. Ultrasonic Imaging 1997;19:19-38. [PubMed: 9286011]

94. Kolen AF, Miller NR, Ahmed EE, Bamber JC. Characterization of cardiovascular liver motion for the eventual application of elasticity imaging to the liver in vivo. Phys Med Biol 2004;49:4187-206. [PubMed: 15509060]

95. Bae U, Dighe M, Dubinsky T, Minoshima S, Shamdasani V, Kim Y. Ultrasound thyroid elastography using carotid artery pulsation: preliminary study. J Ultrasound Med 2007;26:797-805. [PubMed: 17526611]

96. Kolen AF, Bamber JC, Ahmed EE. Analysis of cardiovascular induced liver motion for application to elasticity imaging of the liver in-vivo, (abstract). J Ultrasound Med 2003;21:S53.

97. Baldewsing RA, Danilouchkine MG, Mastik F, Schaar JA, Serruys PW, van der Steen AF. An inverse method for imaging the local elasticity of atherosclerotic coronary plaques. IEEE Trans Inf Technol Biomed 2008;13:277-89. [PubMed: 18693495]

98. Landau, LD.; Lifshitz, EM. Theory of Elasticity. New York: Elsevier; 1986. 
99. Palmeri ML, Wang MH, Dahl JJ, Frinkley KD, NKR. Quantifying hepatic shear modulus in vivo using acoustic radiation force. Ultrasound Med Biol 2008;34:546-58. [PubMed: 18222031]

100. Suki B, Barabasi AL, Lutchen KR. Lung tissue viscoelasticity: a mathematical framework and its molecular basis. J Appl Physiol 1994;76:2749-2759. [PubMed: 7928910]

101. Arbogast KB, Margulies SS. Material characterization of the brainstem from oscillatory shear tests. J Biomech April 1;1998 31:801-807. [PubMed: 9802780]

102. Kim SM, McCulloch TM, Rim K. Comparison of viscoelastic properties of the pharyngeal tissue: human and canine. Dysphagia 1999;14:8-16. [PubMed: 9828269]

103. Lakes RS, Vanderby R. Interrelation of creep and relaxation: a modeling approach for ligaments. J Biomech Eng 1999;121:612-615. [PubMed: 10633261]

104. Yuan H, Kononov S, Cavalcante FSA, Lutchen KR, Ingenito EP, Suki B. Effects of collagenase and elastase on the mechanical properties of lung tissue strips. J Appl Physiol 2000;89:3-14. [PubMed: 10904029]

105. Darvish KK, CJR. Nonlinear viscoelastic effects in oscillatory shear deformation of brain tissue. Med Eng Phys 2001;23:633-645. [PubMed: 11755808]

106. Chen EJ, NJ, Jenkins WK, O'Brien WD Jr. Young's modulus measurements of soft tissues with application to elasticity imaging. IEEE Trans Ultrason Ferroel Freq Cont 1996;43:191-194.

107. Krouskop TA, Wheeler TM, Kallel F, Hall T. The elastic moduli of breast and prostate tissues under compression. Ultrasonic Imaging 1998;20:260-274. [PubMed: 10197347]

108. Yeh WC, Li PC, Jeng YM, Hsu HC, Kuo PL, Li ML, Yang PM, Lee PH. Elastic modulus measurements of human liver and correlation with pathology. Ultrasound Med Biol Apr;2002 28:467-74. [PubMed: 12049960]

109. Han L, Noble JA, Burcher M. A novel ultrasound indentation system for measuring biomechanical properties of in vivo soft tissue. Ultrasound in Med \& Biol 2003;29:813-823. [PubMed: 12837497]

110. Sammani A, Bishop J, Luginbuhl C, Plewes DB. Measuring the elastic modulus of ex vivo small tissue samples. Phys Med Biol 2003;48:2183-2198. [PubMed: 12894978]

111. Ishihara M, Sato M, Sato S, Kikuchi T, Fujikawa K, Kikuchi M. Viscoelastic characterization of biological tissue by photoacoustic measurement. Jpn J Appl Phys 2003;42:L556-L558.

112. Sarvazyan, AP.; Skovorada, AR.; Vucelic, D. Utilization of surface acoustic waves and shear acoustic properties for imaging and tissue characterization, (Unknown), (abstract). 1991.

113. Walz M, Teubner J, Georgi M. Elasticity of benign and malignant breast lesions, Imaging, Application and Results in Clinical and General Practice. Eight International Congress on the Ultrasonic Examination of the Breast 1993;56:56.

114. Kiss MZ, Hobson MA, Varghese T, Harter J, Kliewer MA, Hartenbach EM, Zagzebski JA. Frequency-dependent complex modulus of the uterus: preliminary results. Phys Med Biol 2006;51:3683-95. [PubMed: 16861774]

115. Wen Chun Y, Pai Chi L, Yung Ming J, Hey Chi H, Po Ling K, Meng Lin L, Pei Ming Y, Po Huang L. Elastic modulus measurements of human liver and correlation with pathology. Ultrasound in Medicine \& Biology 2002;28:467-474. [PubMed: 12049960]

116. Ponnekanti H, Ophir J, Huang Y, Cespedes I. Fundamental mechanical limitations on the visualization of elasticity contrast in elastography. Ultrasound Med Biol 1995;21:533-43. [PubMed: 7571146]

117. Kallel F, Bertrand M, Ophir J. Fundamental limitations on the contrast-transfer efficiency in elastography: an analytic study. Ultrasound in Medicine and Biology 1996;22:463-70. [PubMed: 8795173]

118. Varghese T, Ophir J. A theoretical framework for performance characterization of elastography: the strain filter. IEEE Trans Ultrason Ferroel Freq Cont 1997;44:164-72.

119. Varghese T, Ophir J. An analysis of elastographic contrast-to-noise ratio performance. Ultrasound Med Biol 1998;24:915-24. [PubMed: 9740393]

120. Bilgen M. Target detectability in acoustic elastography. IEEE Transactions on Ultrasonics, Ferroelectrics and Frequency Control 1999;46:1128-33.

121. Alam SK, Ophir J, Varghese T. Elastographic axial resolution criteria: an experimental study. IEEE Transactions on Ultrasonics, Ferroelectrics and Frequency Control 2000;47:304-9. 
122. Righetti R, Ophir J, Ktonas P. Axial resolution in elastography. Ultrasound in Medicine and Biology 2002;28:101-13. [PubMed: 11879957]

123. Bilgen M, Insana MF. Error analysis in acoustic elastography. II. Strain estimation and SNR analysis. Journal of the Acoustical Society of America 1997;101:1147-54. [PubMed: 9035402]

124. Srinivasan S, Righetti R, Ophir J. Trade-offs between the axial resolution and the signal-to-noise ratio in elastography. Ultrasound Med Biol 2003;29:847-66. [PubMed: 12837500]

125. Righetti R, Srinivasan S, Ophir J. Lateral resolution in elastography. Ultrasound Med Biol 2003;29:695-704. [PubMed: 12754069]

126. Doyley MM, Meaney PM, Bamber JC. Evaluation of an iterative reconstruction method for quantitative elastography. Physics in Medicine and Biology 2000;45:1521-40. [PubMed: 10870708]

127. Aglyamov S, Skovoroda AR, Rubin JM, O’Donnell M, Emelianov SY. Model-based reconstructive elasticity imaging of deep venous thrombosis. IEEE Trans Ultrason Ferroelectr Freq Control 2004;51:521-31. [PubMed: 15217230]

128. Hiltawsky KM, Kruger M, Starke C, Heuser L, Ermert H, Jensen A. Freehand ultrasound elastography of breast lesions: clinical results. Ultrasound Med Biol 2001;27:1461-9. [PubMed: 11750744]

129. Burnside ES, Hall TJ, Sommer AM, Hesley GK, Sisney GA, Svensson WE, Fine JP, Jiang J, Hangiandreou NJ. Differentiating benign from malignant solid breast masses with US strain imaging. Radiology 2007;245:401-10. [PubMed: 17940302]

130. Regner DM, Hesley GK, Hangiandreou NJ, Morton MJ, Nordland MR, Meixner DD, Hall TJ, Farrell MA, Mandrekar JN, Harmsen WS, Charboneau JW. Breast lesions: evaluation with US strain imaging--clinical experience of multiple observers. Radiology 2006;238:425-37. [PubMed: 16436810]

131. Lyshchik A, Higashi T, Asato R, Tanaka S, Ito J, Mai JJ, Pellot-Barakat C, Insana MF, Brill AB, Saga T, Hiraoka M, Togashi K. Thyroid gland tumor diagnosis at US elastography. Radiology 2005;237:202-11. [PubMed: 16118150]

132. Bharat, S. Electrical and Computer Engineering. Madison: University of Wisconsin-Madison; 2009. Electrode Displacement Strain Imaging for Thermally Ablative Therapies.

133. Kolokythas O, Gauthier T, Fernandez AT, Xie H, Timm BA, Cuevas C, Dighe MK, Mitsumori LM, Bruce MF, Herzka DA, Goswami GK, Andrews RT, Oas KM, Dubinsky TJ, Warren BH. Ultrasound-Based Elastography: A Novel Approach to Assess Radio Frequency Ablation of Liver Masses Performed With Expandable Ablation Probes: A Feasibility Study. J Ultrasound Med 2008;27:935-946. [PubMed: 18499853]

134. Hobson MA, Madsen EL, Frank GR, Jiang J, Shi H, Hall TJ, Varghese T. Anthropomorphic phantoms for assessment of strain imaging methods involving saline-infused sonohysterography. Ultrasound Med Biol 2008;34:1622-37. [PubMed: 18514999]

135. Shi H, Mitchell CC, McCormick M, Kliewer MA, Dempsey RJ, Varghese T. Preliminary in vivo atherosclerotic carotid plaque characterization using the accumulated axial strain and relative lateral shift strain indices. Phys Med Biol 2008;53:6377-94. [PubMed: 18941278]

136. Ribbers H, Lopata RG, Holewijn S, Pasterkamp G, Blankensteijn JD, de Korte CL. Noninvasive two-dimensional strain imaging of arteries: validation in phantoms and preliminary experience in carotid arteries in vivo. Ultrasound Med Biol 2007;33:530-540. [PubMed: 17280769]

137. Schmitt C, Soulez G, Maurice RL, Giroux MF, Cloutier G. Noninvasive vascular elastography: toward a complementary characterization tool of atherosclerosis in carotid arteries. Ultrasound Med Biol 2007;33:1841-1858. [PubMed: 17698283]

138. Maurice RL, Soulez G, Giroux MF, Cloutier G. Noninvasive vascular elastography for carotid artery characterization on subjects without previous history of atherosclerosis. Med Phys 2008;35:34363443. [PubMed: 18777903]

139. de Korte CL, Schaar JA, Mastik F, Serruys PW, van der Steen AF. Intravascular elastography: from bench to bedside. J Interv Cardiol 2003;16:253-9. [PubMed: 12800404]

140. de Korte CL, van der Steen AF, Cepedes EI, Pasterkamp G, Carlier SG, Mastik F, Schoneveld AH, Serruys PW, Bom N. Characterization of plaque components and vulnerability with intravascular ultrasound elastography. Phys Med Biol Jun;2000 45:1465-75. [PubMed: 10870704] 
141. Sridhar M, Insana MF. Ultrasonic measurements of breast viscoelasticity. Med Phys 2007;34:475767. [PubMed: 18196803]

142. Wilson T, Chen Q, Zagzebski JA, Varghese T, VanMiddlesworth L. Initial clinical experience imaging scatterer size and strain in thyroid nodules. J Ultrasound Med 2006;25:1021-9. [PubMed: 16870895]

143. Meixner D, Hangiandreou NJ, Charboneau JW, Hall TJ, Zhu Y, Farrell MA. Initial Clinical Experience with Real-time Ultrasound Strain Imaging of the Thyroid (abstract). RSNA December 1-6;2002 225:713.

144. Alam F, Naito K, Horiguchi J, Fukuda H, Tachikake T, Ito K. Accuracy of sonographic elastography in the differential diagnosis of enlarged cervical lymph nodes: comparison with conventional Bmode sonography. AJR Am J Roentgenol 2008;191:604-10. [PubMed: 18647939]

145. Rubin JM, Xie H, Kim K, Weitzel WF, Emelianov SY, Aglyamov SR, Wakefield TW, Urquhart AG, O'Donnell M. Sonographic elasticity imaging of acute and chronic deep venous thrombosis in humans. J Ultrasound Med 2006;25:1179-86. [PubMed: 16929019]

146. Souchon R, Rouviere O, Gelet A, Detti V, Srinivasan S, Ophir J, Chapelon JY. Visualisation of HIFU lesions using elastography of the human prostate in vivo: preliminary results. Ultrasound Med Biol 2003;29:1007-15. [PubMed: 12878247]

147. Lorenz A, Ermert H, Sommerfeld HJ, Garcia-Schurmann M, Senge T, Philippou S. Ultrasound elastography of the prostate. A new technique for tumor detection (german). Ultraschall Med Feb; 2000 21:8-15. [PubMed: 10746278]

148. Hobson MA, Kiss MZ, Varghese T, Sommer AM, Kliewer MA, Zagzebski JA, Hall TJ, Harter J, Hartenbach EM, Madsen EL. In vitro uterine strain imaging: preliminary results. J Ultrasound Med 2007;26:899-908. [PubMed: 17592053]

149. Thomas A, Kümmel S, Gemeinhardt O, Fischer T. Real-time sonoelastography of the cervix: tissue elasticity of the normal and abnormal cervix. Acad Radiol 2007;14:193-200. [PubMed: 17236992]

150. Mazza E, Nava A, Bauer M, Winter R, Bajka M, Holzapfel GA. Mechanical properties of the human uterine cervix: an in vivo study. Med Image Anal 2006;10:125-36. [PubMed: 16143559]

151. Berry GP, Bamber JC, Armstrong CG, Miller NR, Barbone PE. Towards an acoustic model-based poroelastic imaging method: I. Theoretical foundation. Ultrasound Med Biol 2006;32:547-67. [PubMed: 16616601]

152. Baldewsing RA, Schaar JA, Mastik F, van der Steen AF. Local elasticity imaging of vulnerable atherosclerotic coronary plaques. Adv Cardiol 2007;44:35-61. [PubMed: 17075198]

153. Becker M, Bilke E, Kuhl H, Katoh M, Kramann R, Franke A, Bucker A, Hanrath P, Hoffmann R. Analysis of myocardial deformation based on pixel tracking in two dimensional echocardiographic images enables quantitative assessment of regional left ventricular function. Heart 2005;92:11021108. [PubMed: 16387826]

154. Reisner S, Lysyansky P, Agmon Y, Mutlak D, Lessick J, Friedman Z. Global longitudinal strain: a novel index of left ventricular systolic function. J Am Soc Echocardiography 2004;17:630-633.

155. Suffoletto MS, Dohi K, Cannesson M, Saba S, Gorcsan Jr. Novel speckle-tracking radial strain from routine black-and-white echocardiographic images to quantify dyssynchrony and predict response to cardiac resynchronization therapy. Circulation 2006;113:960-8. [PubMed: 16476850]

156. Konofagou EE, D’Hooge J, Ophir J. Myocardial elastography--a feasibility study in vivo. Ultrasound Med Biol Apr;2002 28:475-82. [PubMed: 12049961]

157. Chen H, Varghese T, Rahko PS, Zagzebski JA. Ultrasound frame rate requirements for cardiac elastography: experimental and in vivo results. Ultrasonics 2009;49:98-111. [PubMed: 18657839]

158. Lee WN, Qian Z, Tosti CL, Brown TR, Metaxas DN, Konofagou EE. Preliminary validation of angle-independent myocardial elastography using MR tagging in a clinical setting. Ultrasound Med Biol 2008;34:1980-97. [PubMed: 18952364]

159. Sandrin L, Fourquet B, Hasquenoph JM, Yon S, Fournier C, Mal F, Christidis C, Ziol M, Poulet B, Kazemi F, Beaugrand M, Palau R. Transient elastography: a new noninvasive method for assessment of hepatic fibrosis. Ultrasound Med Biol 2003;29:1705-13. [PubMed: 14698338]

160. Ophir J, Alam SK, Garra B, Kallel F, Konofagou E, Krouskop T, Varghese T. Elastography: ultrasonic estimation and imaging of the elastic properties of tissues. Proceedings of the Institution of Mechanical Engineers, Part H (Journal of Engineering in Medicine) 1999;213:203-33. 
161. Parker KJ, Taylor LS, Gracewski SM, Rubens DJ. A unified view of imaging the elastic properties of tissue. J Acoust Soc Am 2005;117:2705-12. [PubMed: 15957738]

162. Garra BS. Imaging and estimation of tissue elasticity by ultrasound. Ultrasound Q 2007;23:255-68. [PubMed: 18090836]

163. Greenleaf JF, Fatemi M, Insana MF. Selected methods for imaging elastic properties of biological tissues. Annu Rev Biomed Eng 2003;5:57-78. [PubMed: 12704084]

164. Hall TJ. AAPM/RSNA physics tutorial for residents: topics in US: beyond the basics: elasticity imaging with US. Radiographics 2003;23:1657-71. [PubMed: 14615571] 


\section{Quasi-Static Ultrasound Elastography}

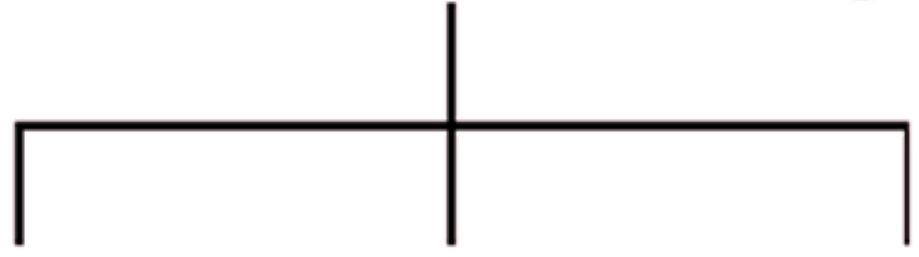

Steady

State

Quasi-Static

Excitation
Steady State

Quasi-Static

Low-frequency

Excitation
Steady State Quasi-Static Physiological Excitation

Figure 1.

Classification of quasi-static ultrasound elastography based on the tissue deformation utilized. 


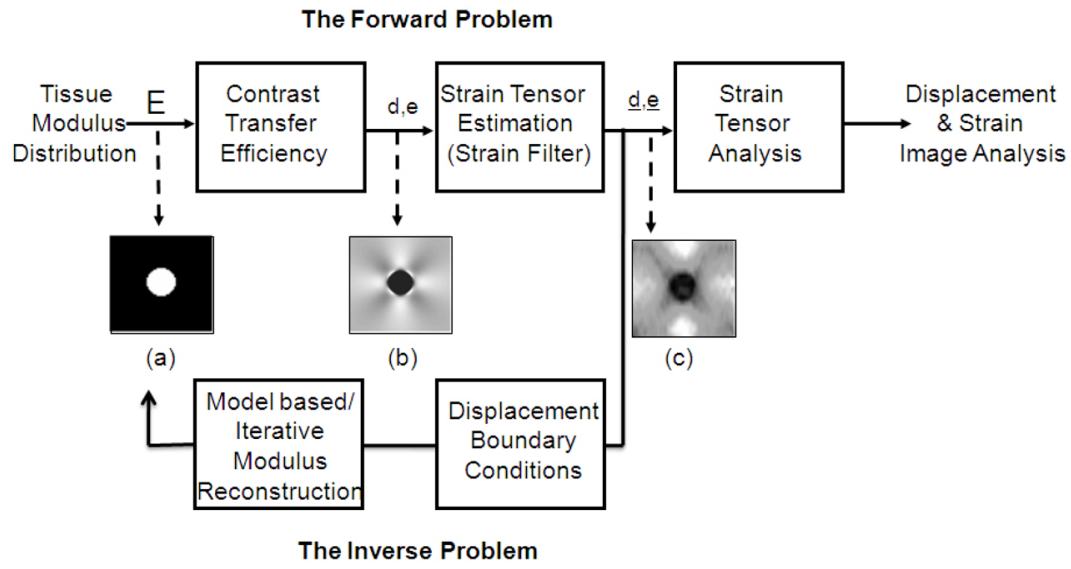

Figure 2.

Block diagram illustrating the forward and inverse problem solutions to obtain strain or modulus distributions for quasi-static elastography. The quasi-static deformation coupled with the underlying tissue elastic modulus distribution (Fig. 2(a)) and the boundary conditions, cause a strain distribution to be set up in the tissue (Fig. 2(b)), based on the contrast transfer efficiency. The statistical properties of the ultrasound based tissue motion estimation process give rise to the Strain Filter. The ideal strain distribution filtered by the strain filter is the estimated displacement and strain distributions respectively (Fig. 2(c)). The estimated displacement coupled with the boundary conditions can be utilized to solve the inverse problem to obtain an estimated modulus distribution. 


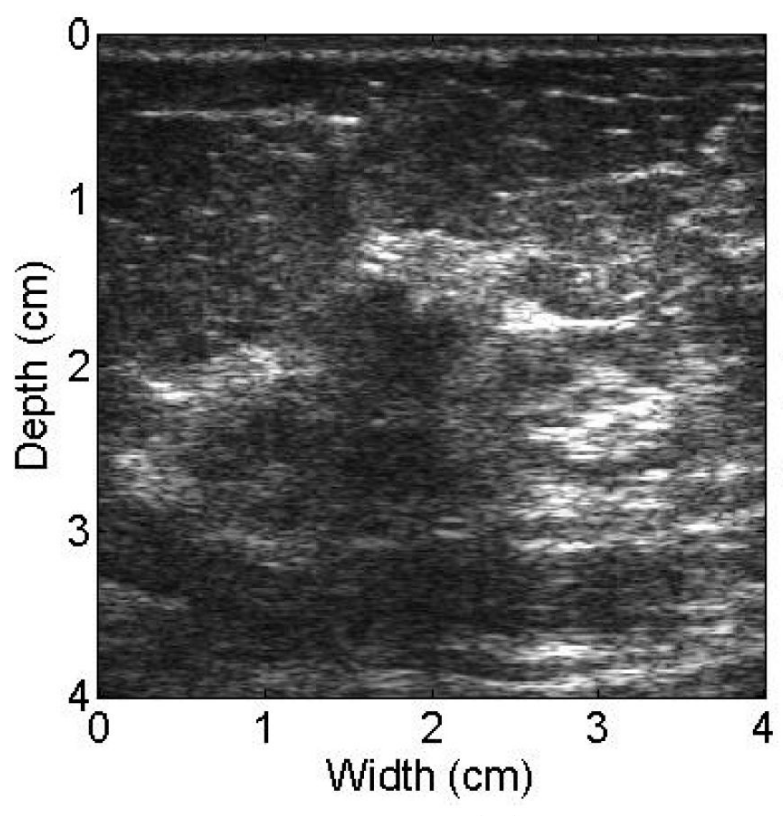

(a)

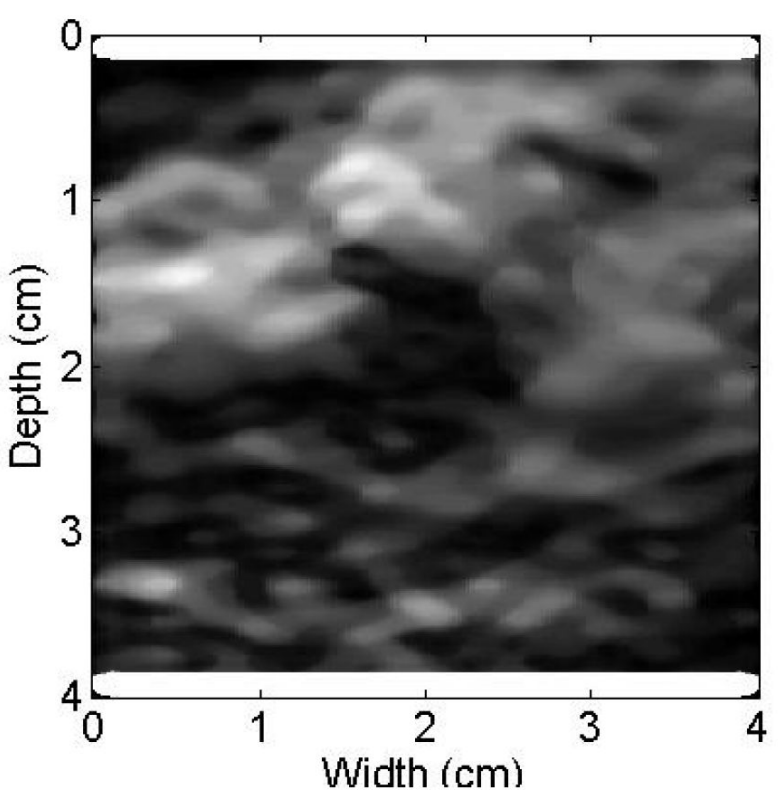

(b)

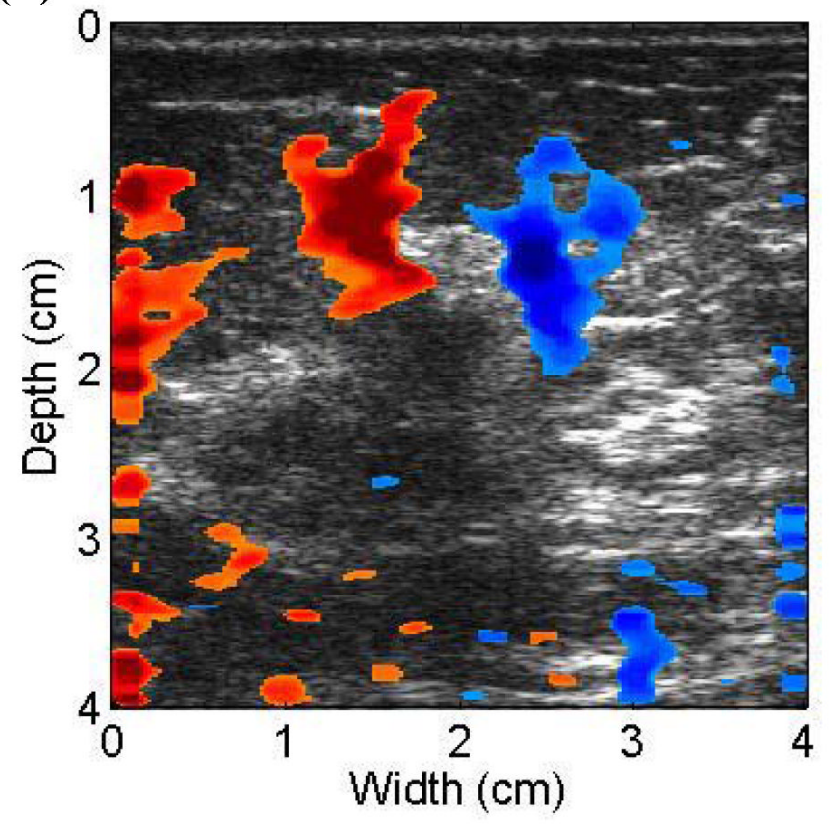

(c)

Figure 3.

In vivo ultrasound B-mode (a), axial strain (b) and shear strain (c) images for a patient diagnosed with an invasive ductal carcinoma. The composite image in (c) is formed by superimposing the axial-shear strains on top of the B-mode image. Radiofrequency data was acquired using a Siemens Antares scanner during real-time palpation imaging at the breast center, UWHospitals and Clinics. 


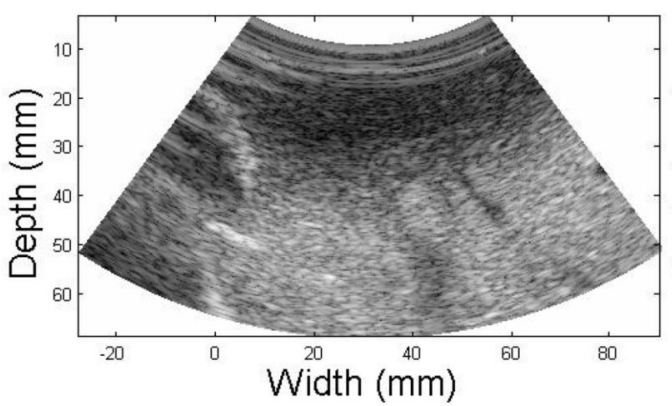

(a)

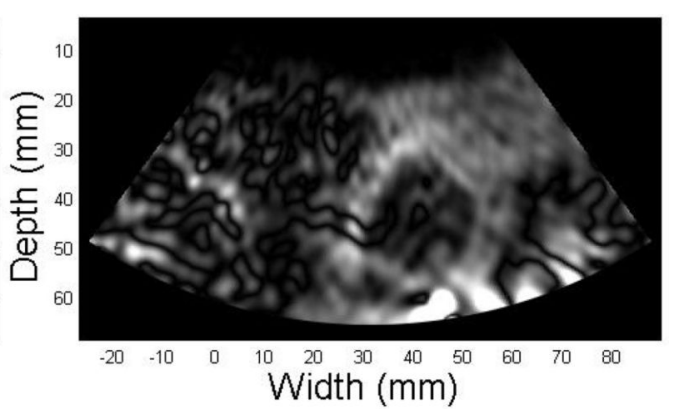

(b)

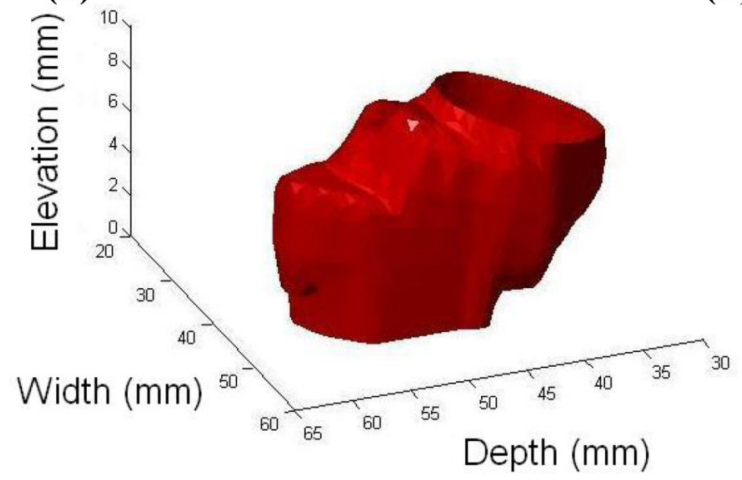

(c)

Figure 4.

Ultrasound in-vivo B-mode (a) 2D axial strain (b) and 3D image (c) of an in-vivo ablated region in the porcine liver obtained using quasi-static electrode displacement elastography.

Radiofrequency data was collected using a Siemens Antares scanner equipped with a C7F2 fourSight four-dimensional ultrasound transducer. 


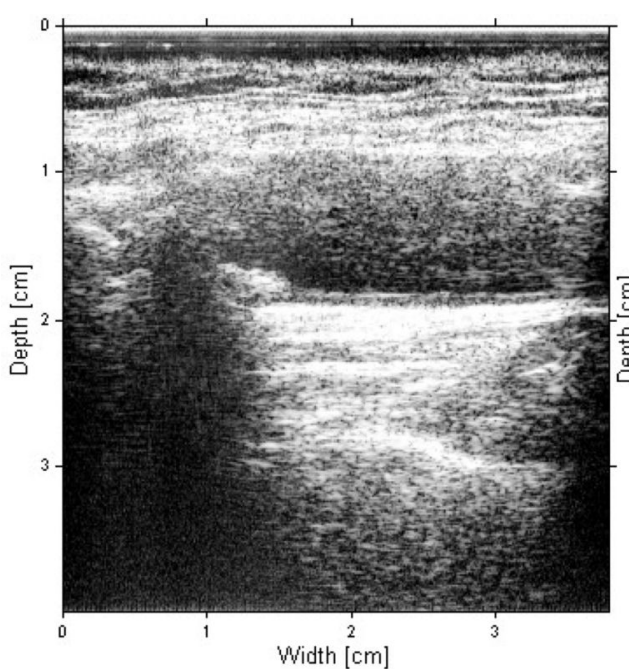

(a)

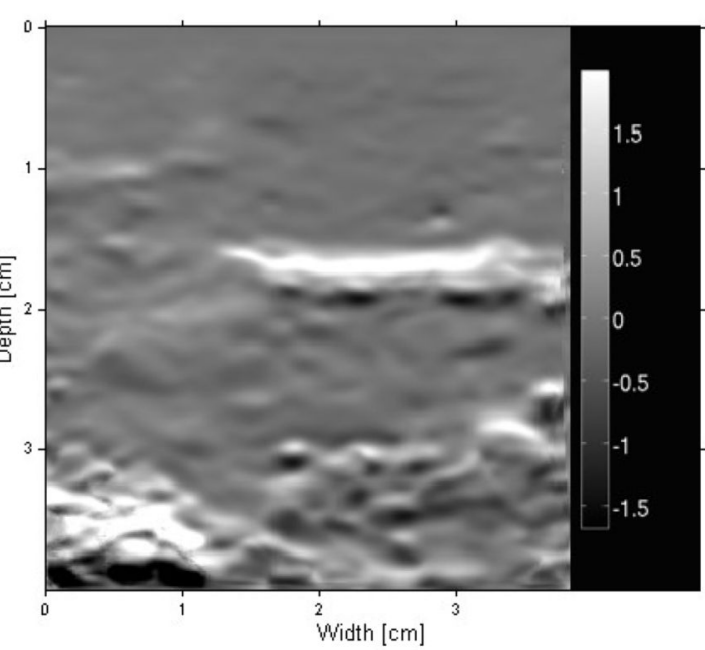

(b)

Figure 5.

Ultrasound in vivo B-mode (a) and axial strain (b) images from the carotid of a patient with atherosclerotic plaque. Brighter or darker regions around the vessel wall indicate softer plaque, while the mid-gray regions denote stiffer plaque. Note the softer plaque region attached to the bottom wall of the artery from $1.5-4 \mathrm{~cm}$ at a depth of $2 \mathrm{~cm}$. Hyperechogenic regions around the vessel wall along with the areas of shadowing appear mid-gray denoting stiffer plaque regions. Radiofrequency data was acquired using a Siemens Antares scanner, UW-Madison Hospitals and Clinics. 


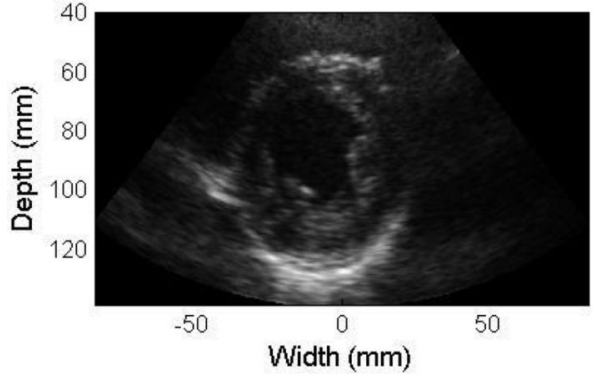

(a)

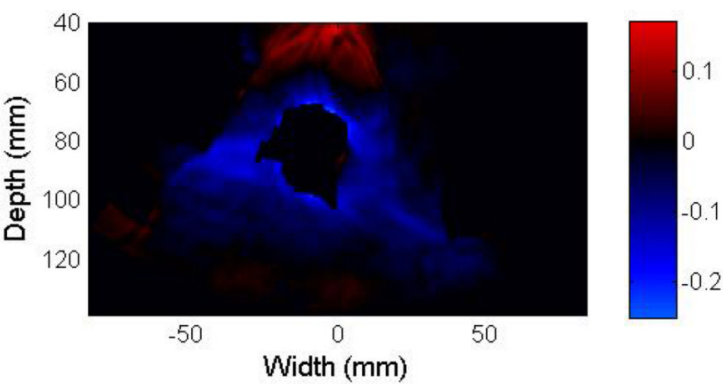

(b)

Figure 6.

In vivo short-axes echocardiogram (a) and axial strain image (b) for a patient in systole. Data acquired using a GE Vivid 7 scanner, UW-Madison Hospitals and Clinics. 